\title{
Triple stent-in-stent placement of novel braided metal stents with a slim delivery system via balloon-assisted enteroscopy
}

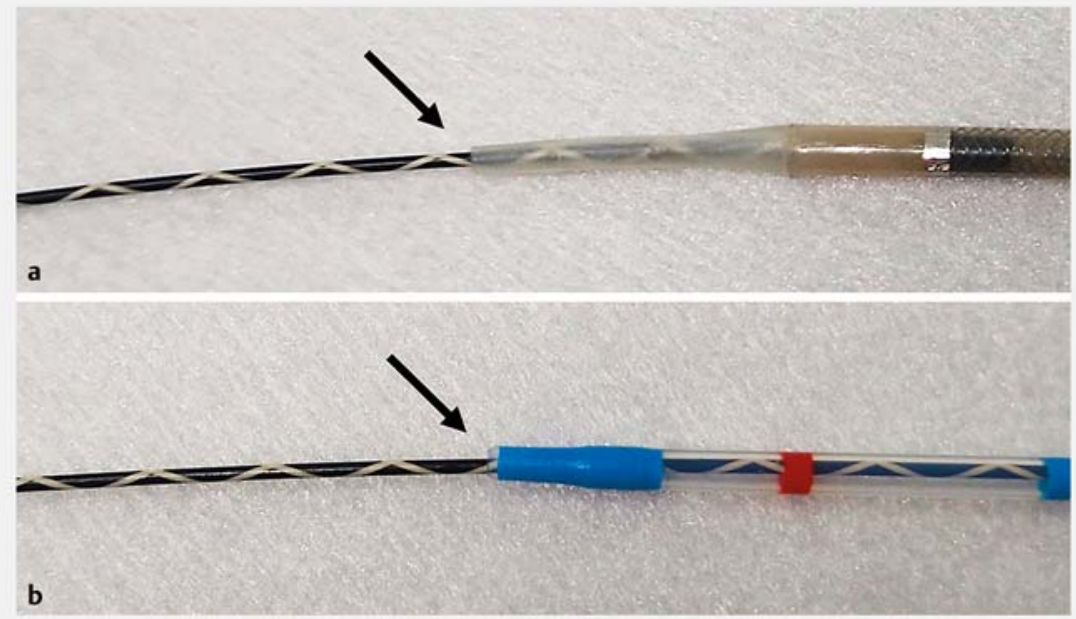

- Fig. 1 Photographs showing how: a the novel braided uncovered metal stent with a 6-Fr delivery system (Niti-S large cell SR slim delivery; TaeWoong Medical, Gyeonggi-do, Korea) has a well-tapered tip, which can reduce the gap between the stent delivery system and the 0.025 -inch guidewire in comparison to: $\mathbf{b}$ the gap between a 0.025 -inch guidewire and the tip of an ERCP catheter designed for this size of guidewire (MTW Endoskopie, Wesel, Germany).
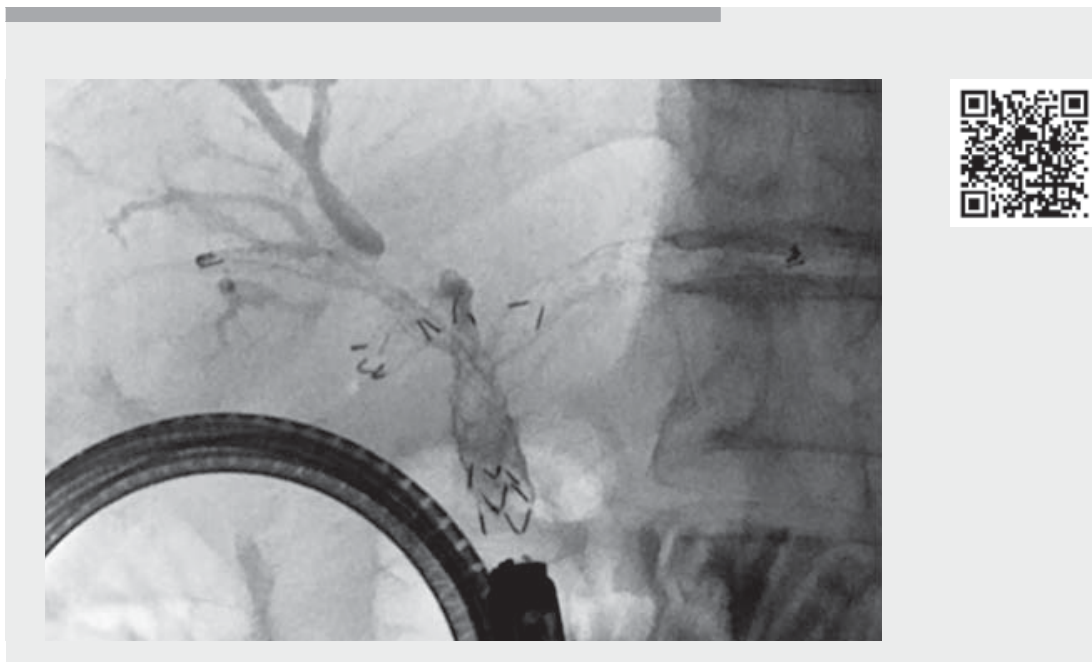

Video 1 Triple stent-in-stent placement of novel braided metal stents with a slim delivery system via balloon-assisted enteroscopy for hilar malignant biliary obstruction.

The placement of multiple metal stents for hilar malignant biliary obstruction $(\mathrm{MBO})$ is technically challenging, especially for patients with surgically altered anatomy [1]. The laser-cut type of met- al stent has been the only choice [2] until now, with the advent of a novel braided-type metal stent with a 6-Fr delivery system (Niti-S large cell SR slim delivery; 196-cm long; TaeWoong

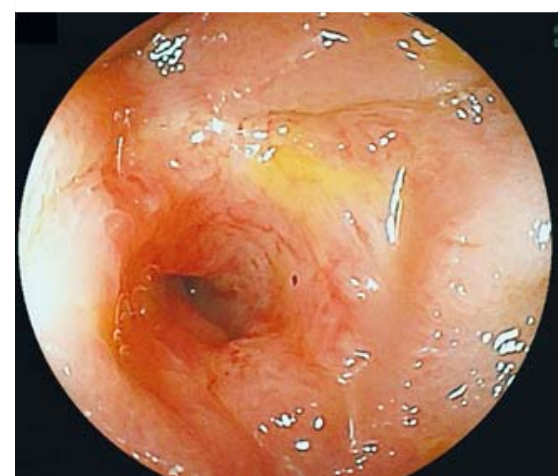

Pig. 2 Endoscopic image of the hepaticojejunostomy anastomosis, which was obstructed by perihilar cholangiocarcinoma.

Medical, Gyeonggi-do, Korea) ( Fig. 1) $[3,4]$, which can be deployed via balloon enteroscopy-assisted endoscopic retrograde cholangiopancreatography (ERCP). With its improvement in pushability and trackability, multiple stentin-stent placement may now be a feasible option for post-surgical MBO.

An 81-year-old man was admitted for the management of MBO due to an unresectable perihilar cholangiocarcinoma. He had a history of pancreaticoduodenectomy and hepaticojejunostomy with Billroth-Il reconstruction for pancreatic cancer 3 years previously. A short-type double-balloon assisted-endoscope (El-580BT; Fujifilm Corp., Tokyo, Japan), with a working channel of $3.2 \mathrm{~mm}$ in diameter [5], was advanced to the site of the anastomosis, which was obstructed by the tumor ( $\triangleright$ Fig. 2; $\triangleright$ Video 1 ). A cholangiogram revealed that three main biliary branches (the left hepatic duct, right anterior branch, and right posterior branch) were completely separated ( Fig.3a).

First, a novel braided uncovered metal stent was placed in the bile duct at segment 6 (B6) over a 0.025-inch guidewire (VisiGlide2; Olympus, Tokyo, Japan). The guidewire was then placed in B2 through 

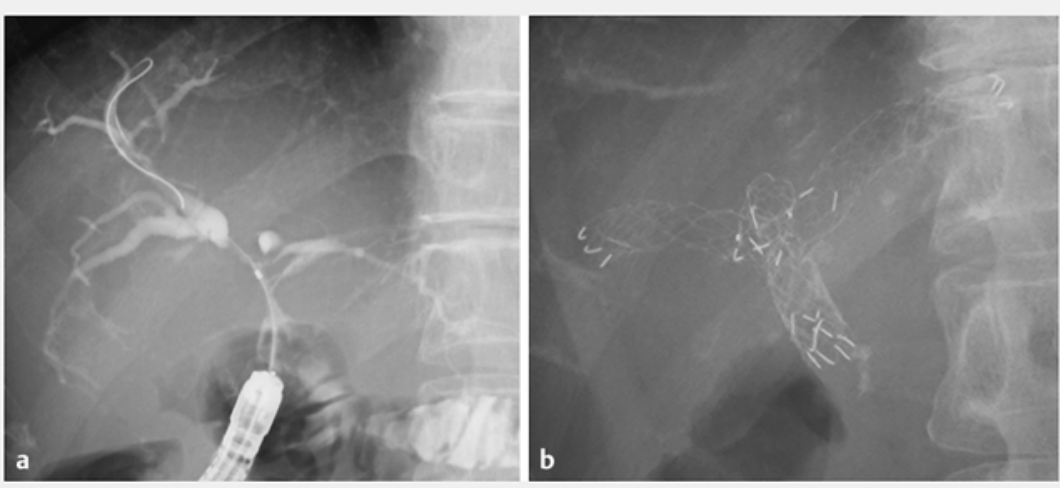

Fig. 3 Cholangiographic images: a suggesting a perihilar malignant biliary obstruction classified as Bismuth type IV in a patient with a history of pancreaticoduodenectomy; $\mathbf{b}$ the triple stent-in-stent placement using a novel braided metal stent with a 6-Fr delivery system via a double-balloon assisted-endoscope.

the mesh of the first stent; however, an ERCP catheter (MTW Endoskopie, Wesel, Germany) designed for the 0.025 -inch guidewire could not be passed through the stent mesh. Because the tip of the delivery system is well-tapered ( $\triangleright$ Fig. 1 ), we then tried inserting the metal stent directly without any dilation and readily succeeded in passing this through the mesh. After a cholangiogram had been obtained by injecting contrast medium through the delivery system itself, the second stent was deployed. Finally, the third stent could also be easily advanced into B8 through the two overlapped stents ( $\triangleright$ Fig. $\mathbf{3}$ b).

Endoscopy_UCTN_Code_TTT_1AR_2AK

\section{Competing interests}

Dr Y. Nakai has received a lecture fee and a research grant from Fujifilm Medical, a lecture fee and a research grant from Century Medical, Inc., and a lecture fee from Olympus. The remaining authors declare that they have no conflict of interest.
The authors

Tatsuya Sato ${ }^{1}$, Hirofumi Kogure ${ }^{1}$, Yousuke Nakai $^{1,2}$, Kazunaga Ishigaki ${ }^{1}$, Ryunosuke Hakuta $^{1,2}{ }^{\text {, Kei Saito }}{ }^{1}$, Kazuhiko Koike ${ }^{1}$

1 Department of Gastroenterology, Graduate School of Medicine, The University of Tokyo, Tokyo, Japan

2 Department of Endoscopy and Endoscopic Surgery, The University of Tokyo, Tokyo, Japan

\section{Corresponding author}

Yousuke Nakai, MD, PhD

Department of Endoscopy and Endoscopic Surgery, The University of Tokyo, 7-3-1 Hongo, Bunkyo-ku, Tokyo 113-8655, Japan ynakai-tky@umin.ac.jp

\section{References}

[1] Tomoda T, Kato H, Miyamoto K et al. Outcomes of endoscopic treatment for malignant biliary obstruction in patients with surgically altered anatomy: analysis of risk factors for clinical failure. Surg Endosc 2020; 35: $232-238$
[2] Kogure H, Yamada A, Isayama H et al. Multiple metal stenting using a double-balloon endoscope for malignant biliary obstruction in a patient with hepaticojejunostomy. Endoscopy 2014; 46 : E472-E473

[3] Takenaka M, Nakai A, Kudo M. Novel concept of bared type metallic stent for endoscopic bilateral stent-in-stent placement in patients with hilar malignant biliary obstruction (with video). J Hepatobiliary Pancreat Sci 2020; 27: 282-283

[4] Inoue T, Ibusuki M, Kitano R et al. A novel large cell-sized stent with slim delivery for combined side-by-side and stent-in-stent placement in malignant hilar biliary obstruction. Endoscopy 2020; 52: E104-E105

[5] Yamada A, Kogure H, Nakai Y et al. Performance of a new short-type double-balloon endoscope with advanced force transmission and adaptive bending for pancreaticobiliary intervention in patients with surgically altered anatomy: A propensitymatched analysis. Dig Endosc 2019; 31: 86-93

\section{Bibliography}

Endoscopy 2022; 54: E224-E225

DOI 10.1055/a-1492-1911

ISSN 0013-726X

published online 31.5.2021

(c) 2021. Thieme. All rights reserved.

Georg Thieme Verlag KG, Rüdigerstraße 14, 70469 Stuttgart, Germany

ENDOSCOPY E-VIDEOS

https:/|eref.thieme.de/e-videos

回回 Endoscopy E-Videos is an open access online section, 靣: reporting on interesting cases and new techniques in gastroenterological endoscopy. All papers include a high quality video and all contributions are freely accessible online. Processing charges apply (currently EUR 375), discounts and wavers acc. to HINARI are available.

This section has its own submission website at https://mc.manuscriptcentral.com/e-videos 